\title{
Discontinuing Hemodialysis with Patient Care and a Successful 9-Year Follow-up in a Patient Presumed to Have End-Stage Kidney Disease Scheduled to Lifelong Hemodialysis: A Case Report
}

\author{
Omer Toprak ${ }^{1, *(1)}$, Emel Aslan Bozyel ${ }^{2}$ and Burak Alp ${ }^{2}$ \\ 1 Department of Medicine, Division of Nephrology, Balikesir University School of Medicine, \\ 10145 Balikesir, Turkey \\ 2 Department of Medicine, Division of Internal Medicine, Balikesir University School of Medicine, \\ 10145 Balikesir, Turkey; emelaslan006@hotmail.com (E.A.B.); burakalp316@gmail.com (B.A.) \\ * Correspondence: omertoprak@balikesir.edu.tr; Tel.: +90-507-2589585; Fax: +90-266-6121023
}

Received: 7 December 2020; Accepted: 17 February 2021; Published: 26 February 2021

\begin{abstract}
End-stage kidney disease patients who require hemodialysis for more than 3 months have a small chance of leaving dialysis unless they have a kidney transplant. Educating the patient about lifestyle changes can play a major role in improving kidney function. Therefore, we created a patient education program according to our nephrology experiences. Herein, we show an end-stage kidney disease patient who underwent hemodialysis for 6 months. Afterwards, dialysis was terminated with patient care, and the patient was then followed up for 9 years without dialysis. To date, there have been no reports regarding the termination of long-term dialysis with a kidney care program and the ensuing 9-year follow-up without renal replacement therapy.
\end{abstract}

Keywords: patient care; hemodialysis; end-stage kidney disease; renal function recovery

\section{Introduction}

About 2.5 million patients worldwide require dialysis or kidney transplants. Patients who need renal replacement therapy are also increasing day-by-day [1]. It is unfortunately impossible to accommodate such a large number of renal replacement therapy patients. As such, millions of patients die because they are not able to have dialysis or find a donor candidate for kidney transplantation. At this point, it is very important to educate patients and their caregivers about chronic kidney disease (CKD), which will hopefully postpone the need for dialysis or kidney transplantation. Kidney care programs play a role in kidney function [2-5], including Toprak's Kidney Care, which provides patient and caregiver trainings, suggests lifestyle changes, promotes regular nutrition and exercise, supplies adequate drugs in proper doses, improves morale and motivation, regulates fluid status, preserves residual kidney function, and offers nephroprotective alternative medicines.

In this paper, we present a patient evaluated to have end-stage kidney disease (ESKD), as well as diabetic nephropathy and an arteriovenous fistula. Thus, permanent vascular access was included in a lifelong dialysis program. However, the patient was removed on patient care after 6 months of hemodialysis and did not need hemodialysis for 9 years afterward. Although this case report is a single case, it is promising because it emphasizes that long-term dialysis treatment can be terminated with careful and strict patient care. Further, these patients can live healthily for many years. The start of dialysis should not be a barrier to research the possibility of discontinuing dialysis in CKD patients who have enough urination. 


\section{Case Report}

In March 2010, a 71-year-old patient applied to the nephrology outpatient clinic because of hemodialysis regulation. We hospitalized the patient for nephrological evaluation. In our medical history, we found that the patient had suffered from hypertension for 10 years, type 2 diabetes mellitus for 15 years, and ESKD due to diabetic nephropathy for 2 years. In addition, the patient and her caregiver were noted to have clinical depression and anxiety. Before starting dialysis, the patient had a hemodialysis certified specialist for 20 months, and an arteriovenous fistula was placed in her left arm. Hemodialysis started in September 2009 due to uncontrolled hypertension and a glomerular filtration rate (GFR) of $8.4 \mathrm{~mL} / \mathrm{min} / 1.73 \mathrm{~m}^{2}$.

She underwent hemodialysis for 6 months, 3 times a week, and $4 \mathrm{~h}$ in each session. The day the patient was admitted to us was the patient's routine dialysis day. She was stable and had $800 \mathrm{cc} /$ day of urine. A laboratory analysis revealed anemia, hypopotassemia, hypomagnesemia, hypophosphatemia, hypoalbuminemia, mild acidosis, and an eGFR of $11.2 \mathrm{~mL} / \mathrm{min} / 1.73 \mathrm{~m}^{2}$ (Table 1). On the renal ultrasound, we found a bilateral normal-sized parenchymal thickness and bilateral grade 1 echogenicity kidneys. We started to correct the patient's electrolyte abnormalities and malnutrition by changing the meditation and suggesting new lifestyle and nutritional habits according to Toprak's Kidney Care (Tables 2 and 3). We added sodium bicarbonate, erythropoietin, multi-vitamins, magnesium, vitamin $\mathrm{D}$, and calcium acetate to the treatment and adjusted the insulin dose. During hemodialysis, the dry weight of the patient was determined to be $65 \mathrm{~kg}$. Approximately $1 \mathrm{~L}$ of fluid was ultrafiltrated in each session, and the patient was allowed to consume a total of $700 \mathrm{cc}$ of water and $300 \mathrm{cc}$ of other liquids. However, because there was no hypervolemia, we allowed her to drink $1.5 \mathrm{~L}$ of water and $500 \mathrm{cc}$ of other fluids per day. We did not take the patient on dialysis for 6 days in the hospital because of clinical and laboratory findings. As expected, an increase in serum urea and creatinine values was detected after 6 days. Moderate hyponatremia was also detected on the sixth day of her admission. Therefore, we reduced her daily water intake to $1250 \mathrm{cc}$. We did not find any uremic symptoms, encephalopathy, acidosis, uncontrolled hypertension, hyponatremia, hyperphosphatemia, hyperpotassemia, or fluid overload, and the urine output was sufficient. GFR levels were fixed at about $9 \mathrm{~mL} / \mathrm{min} / 1.73 \mathrm{~m}^{2}$ (Table 1). There was no indication of hemodialysis. The depression and anxiety of the patient and her caregiver improved. According to the clinical and laboratory findings, we decided to end dialysis on 8 March 2010. We followed-up our patient for 9 years without dialysis.

During this follow-up period, GFR values increased up to $30.8 \mathrm{~mL} / \mathrm{min} / 1.73 \mathrm{~m}^{2}$. The patient and her caregiver attended our training seminars. Seven years later, we found that the bilateral small ( $85 \mathrm{~mm}$ vs. $75 \mathrm{~mm}$ ) kidneys showed decreased parenchymal thickness (9 mm vs. $10 \mathrm{~mm}$ ). During the follow-up, the patient was hospitalized 4 times. Three of these hospitalizations were caused by a resistant urinary tract infection, while one was due to pneumonia and hyponatremia. During these hospitalizations and acute infectious periods, acute kidney injury (AKI) occurred only during the patient's first hospitalization (29 July 2015). The creatinine value increased from $1.6 \mathrm{mg} / \mathrm{dL}$ to $2.1 \mathrm{mg} / \mathrm{dL}$ and then regressed to $1.9 \mathrm{mg} / \mathrm{dL}$ after appropriate medical treatment. There was no reduction in the urine output. There were no major adverse cardiac events. All hospitalizations and treatments were managed by the same nephrologist. In each outpatient clinic appointment, we reviewed whether our recommendations for eating, drinking, lifestyle, and medication use were implemented by the patient through a standard questionnaire. Our patient largely complied with the exact serving sizes we suggested during the 9 -year follow-up period. The patient lived for 9 years without the need for dialysis. The caregiver who brought the patient to the hospital died in 2019, and we lost contact with the patient after the last control in March 2019, when the patient was 81 years old. 
Table 1. Renal, metabolic, nutritional, and fluid load parameters of the patient.

\begin{tabular}{|c|c|c|c|c|c|c|c|c|}
\hline & First Start to HD & HD Stopped & $\begin{array}{l}\text { HD Free } \\
3 \text { Days }\end{array}$ & $\begin{array}{c}\text { HD Free } \\
6 \text { Days }\end{array}$ & $\begin{array}{l}\text { HD Free } \\
1 \text { Year }\end{array}$ & $\begin{array}{c}\text { HD Free } \\
3 \text { Years }\end{array}$ & $\begin{array}{c}\text { HD Free } \\
7 \text { Years }\end{array}$ & $\begin{array}{c}\text { HD Free } \\
9 \text { Years }\end{array}$ \\
\hline Date & 2 September 2009 & 3 March 2010 & 5 March 2010 & 8 March 2010 & 1 April 2011 & 25 February 2013 & 30 January 2017 & 26 March 2019 \\
\hline \multicolumn{9}{|l|}{ Renal Parameters } \\
\hline Creatinine, $\mathrm{mg} / \mathrm{dL}$ & 4.9 & 3.8 & 4.8 & 4.7 & 2.5 & 2.1 & 2.0 & 2.2 \\
\hline Urea, mg/dL & 158 & 52 & 94 & 144 & 118 & 113 & 109 & 115 \\
\hline eGFR, $\mathrm{mL} / \mathrm{min} / 1.73 \mathrm{~m}^{2}$ & 8.4 & 11.2 & 8.5 & 8.7 & 18.6 & 22.6 & 23.3 & 20.5 \\
\hline Urine amount, mL/day & 1500 & 800 & 1200 & 1600 & 1700 & 1500 & 2000 & 1700 \\
\hline Blood pressure, $\mathrm{mmHg}$ & $210 / 120$ & $130 / 70$ & $130 / 70$ & $130 / 70$ & $100 / 60$ & $130 / 80$ & $150 / 80$ & $150 / 70$ \\
\hline Urine $\mathrm{P} / \mathrm{C}, \mathrm{mg} / \mathrm{mg}$ & & 180 & & 220 & 140 & 510 & 1137 & 4097 \\
\hline Blood pH & 7.26 & 7.31 & 7.36 & 7.33 & 7.42 & 7.38 & 7.44 & \\
\hline Blood $\mathrm{HCO}_{3}, \mathrm{mEq} / \mathrm{L}$ & 16 & 19 & 21 & 20 & 23 & 22 & 22 & \\
\hline Parathormone, pg/mL & & 192 & & & 283 & 214 & 157 & 169 \\
\hline Sodium, $\mathrm{mEq} / \mathrm{L}$ & 128 & 142 & 139 & 129 & 140 & 149 & 141 & 139 \\
\hline Potassium, $\mathrm{mEq} / \mathrm{L}$ & 4.9 & 3.0 & 3.8 & 3.7 & 5.8 & 5.4 & 4.8 & 4.5 \\
\hline Calcium, mg/dL & 7.8 & 8.4 & 7.6 & 7.1 & 7.4 & 8.4 & 9.4 & 8.7 \\
\hline Phosphorus, mg/dL & 5.9 & 1.4 & 2.8 & 3.0 & 5.2 & 3.9 & 3.7 & 3.9 \\
\hline Magnesium, mg/dL & & 1.6 & & 1.8 & 3.2 & 2.0 & 2.1 & 2.0 \\
\hline \multicolumn{9}{|l|}{ Kidney Ultrasound } \\
\hline Linear dimension, $\mathrm{mm}$ & & $100 / 92$ & & & & & $85 / 75$ & \\
\hline Echogenity (grade) & & $1 / 1$ & & & & & $1 / 1$ & \\
\hline Parenchymal thickness & & $15 / 15$ & & & & & $9 / 10$ & \\
\hline \multicolumn{9}{|l|}{ Volume Parameters } \\
\hline Pretibial oedema & $+/+$ & $-1-$ & $-1-$ & $-1-$ & $-1-$ & $-1-$ & $-/+$ & $++/++$ \\
\hline Pleural effusion, $\mathrm{cm}$ & $0 / 0$ & $0 / 0$ & & $0 / 0$ & $0 / 0$ & & & $0 / 0$ \\
\hline Pericardial effusion, $\mathrm{cm}$ & & 0 & & 0 & 0 & & & 0 \\
\hline Cardiothoracic ratio & 0.51 & 0.47 & & 0.50 & 0.48 & & 0.50 & \\
\hline Metabolic Parameters & & & & & & & & \\
\hline
\end{tabular}


Table 1. cont.

\begin{tabular}{|c|c|c|c|c|c|c|c|c|}
\hline & First Start to HD & HD Stopped & $\begin{array}{l}\text { HD Free } \\
3 \text { Days }\end{array}$ & $\begin{array}{c}\text { HD Free } \\
6 \text { Days }\end{array}$ & $\begin{array}{c}\text { HD Free } \\
1 \text { Year }\end{array}$ & $\begin{array}{c}\text { HD Free } \\
3 \text { Years }\end{array}$ & $\begin{array}{c}\text { HD Free } \\
7 \text { Years }\end{array}$ & $\begin{array}{c}\text { HD Free } \\
9 \text { Years }\end{array}$ \\
\hline Date & 2 September 2009 & 3 March 2010 & 5 March 2010 & 8 March 2010 & 1 April 2011 & 25 February 2013 & 30 January 2017 & 26 March 2019 \\
\hline BMI, $\mathrm{kg} / \mathrm{m}^{2}$ & 27.05 & 25.15 & 25.34 & 25.15 & 24.77 & 27.05 & 27.05 & 28.58 \\
\hline Weight, kg & 71 & 66.0 & 66.5 & 66.0 & 65.0 & 71.0 & 71.0 & 75.0 \\
\hline Hemoglobin, mg/dL & 9.3 & 10.4 & 9.9 & 9.5 & 12.8 & 11.2 & 13.2 & 10.8 \\
\hline Albumine, gr/dL & 2.7 & 2.8 & & 3.2 & 3.7 & 4.2 & & 3.9 \\
\hline Uric acid, $\mathrm{mg} / \mathrm{dL}$ & 8.9 & 8.0 & & 6.7 & 7.6 & 6.2 & 7.3 & 7.0 \\
\hline Glucose, mg/dL & 157 & 142 & 67 & 113 & 118 & 129 & 167 & 109 \\
\hline $\mathrm{HbA}_{1} \mathrm{C}, \%$ & & 6.1 & & & 7.1 & 6.4 & 8.0 & \\
\hline HDL-C, mg/dL & & 41 & & & & 74 & & \\
\hline LDL-C, mg/dL & & 72 & & & & 133 & & \\
\hline Triglyceride, mg/dL & & 107 & & & & 111 & & \\
\hline
\end{tabular}

Abbreviations: HD—hemodialysis; eGFR—estimated glomerular filtration rate, estimated via the CKD-EPI (chronic kidney disease epidemiology collaboration) equation; urine P/C—urine protein to creatinine ratio; NA—not available; LVEF—left ventricular ejection fraction; BMI—body mass index; HDL-C—high-density lipoprotein cholesterol; LDL-C—low-density lipoprotein cholesterol.

Table 2. Educational, clinical, and lifestyle parameters of the patient secondary to patient care.

\begin{tabular}{|c|c|c|c|c|c|c|c|c|}
\hline & Basal & Day 3 & Day 6 & Year 1 & Year 3 & Year 5 & Year 7 & Year 9 \\
\hline & \multicolumn{8}{|c|}{ Hemodialysis-Free Time (9 Years) } \\
\hline \multicolumn{9}{|l|}{ Educational/Patient Related Activities } \\
\hline Patient and caregiver education, total hours & 0 & 6 & 12 & 24 & 48 & 72 & 96 & 110 \\
\hline Spiritual support, total number & 0 & 1 & 2 & 5 & 11 & 17 & 23 & 29 \\
\hline Approval from nephrologist in all drugs & - & + & + & + & + & + & + & + \\
\hline All controls with the same nephrologist & - & + & + & + & + & + & + & + \\
\hline Hospitalization for any reason, number & 1 & 0 & 0 & 0 & 0 & 2 & 2 & 0 \\
\hline Major adverse cardiac events, number & 0 & 0 & 0 & 0 & 0 & 0 & 0 & 0 \\
\hline
\end{tabular}


Table 2. cont.

\begin{tabular}{|c|c|c|c|c|c|c|c|c|}
\hline & Basal & Day 3 & Day 6 & Year 1 & Year 3 & Year 5 & Year 7 & Year 9 \\
\hline & \multicolumn{8}{|c|}{ Hemodialysis-Free Time (9 Years) } \\
\hline \multicolumn{9}{|l|}{ Medications Used by Patient } \\
\hline Sodium carbonate, $500 \mathrm{mg} 3$ times/day & - & + & + & + & + & + & + & + \\
\hline Multivitamin (B, C, folat), twice/week & - & + & + & + & + & + & + & + \\
\hline Darbepoetin alfa, 20 to $50 \mathrm{mcg} /$ week & - & + & - & + & + & - & - & + \\
\hline Calcitriol $0.25 \mathrm{mcg} /$ day if necessary & - & + & + & + & + & + & + & + \\
\hline Calcium acetate, $500 \mathrm{mg} 3$ times/day & - & - & + & + & + & - & - & + \\
\hline Magnesium oxide, $365 \mathrm{mg}$ once/day & - & + & + & + & + & - & - & - \\
\hline Allopurinol, $150 \mathrm{mg}$ twice/week & - & - & - & + & - & + & - & - \\
\hline Paracetamol, $500 \mathrm{mg}$ once/week & - & - & - & + & + & + & + & + \\
\hline Insulin glargine, 12 to 6 units/once-daily & + & + & + & + & + & + & + & + \\
\hline Furosemide 20 to $40 \mathrm{mg}$ twice/week & - & - & - & - & - & + & + & + \\
\hline Lacidipine, $4 \mathrm{mg} /$ day & - & - & - & - & - & + & + & + \\
\hline Polystyrene sulfonate, $880 \mathrm{mg} /$ day & - & - & - & + & - & - & - & - \\
\hline Nephrotoxic antibiotics or herbals & - & - & - & - & - & - & - & - \\
\hline Non-steroidal anti-inflammatory drugs & - & - & - & - & - & - & - & - \\
\hline Iodinated contrast use without prophylaxis & - & - & - & - & - & - & - & - \\
\hline \multicolumn{9}{|l|}{ Depression/Anxiety } \\
\hline Beck depression score (patient) & 34 & & & 7 & 6 & & 5 & \\
\hline Beck anxiety score (patient) & 42 & & & 6 & 6 & & 4 & \\
\hline Beck depression score (caregiver) & 30 & & & 5 & 5 & & 5 & \\
\hline Beck anxiety score (caregiver) & 32 & & & 4 & 4 & & 5 & \\
\hline \multicolumn{9}{|l|}{ Lifestyle Changes } \\
\hline Exercise, minutes/day & 5 & 10 & 15 & 30 & 40 & 45 & 45 & 45 \\
\hline Sleeping, hours/day & 4 & 4 & 5 & 7 & 7 & 8 & 8 & 8 \\
\hline Sunbathe, $30 \mathrm{~min}, 3$ times/week & - & - & + & + & + & + & + & + \\
\hline Smoking or alcohol intake & - & - & - & - & - & - & - & - \\
\hline High salt intake, $>4 \mathrm{~g} /$ day & + & - & - & - & - & - & - & - \\
\hline
\end{tabular}

Abbreviations: BAI-Beck anxiety inventory (8-15: mild, 16-25: moderate, 26-63: severe); BDI—Beck depression inventory (10-18: mild, 19-29: moderate, 30-63: severe). 
Table 3. Eating and drinking habits of the patient secondary to patient care.

\begin{tabular}{|c|c|c|c|c|c|c|c|c|}
\hline & Basal & Day 3 & Day 6 & Year 1 & Year 3 & Year 5 & Year 7 & Year 9 \\
\hline & \multicolumn{8}{|c|}{ Hemodialysis-Free Time (9 Years) } \\
\hline \multicolumn{9}{|l|}{ Probiotic Consumption } \\
\hline Homemade yogurt, $35 \mathrm{~g} /$ day & - & - & - & + & + & + & + & + \\
\hline Apple or jujube vinegar, $3 \mathrm{~mL} /$ day & - & - & - & + & + & + & + & + \\
\hline Special sauerkraut ${ }^{\mathrm{a}}, 30 \mathrm{~g} /$ day & - & - & - & + & + & + & + & + \\
\hline \multicolumn{9}{|l|}{ Fruit Consumption } \\
\hline Green sour apple, $90 \mathrm{~g} /$ day & - & + & + & + & + & + & + & + \\
\hline Watermelon, $200 \mathrm{~g} /$ week & + & + & + & + & + & + & + & + \\
\hline Lemon, $120 \mathrm{~g} /$ week & + & + & + & + & + & + & + & + \\
\hline Fruits other than those listed above & + & - & - & - & - & - & - & - \\
\hline \multicolumn{9}{|l|}{ Meat Consumption } \\
\hline Beef, lamb, or mutton, $300 \mathrm{~g} /$ week & + & + & + & + & + & + & + & + \\
\hline Processed, frozen, or canned meats & + & - & - & - & - & - & - & - \\
\hline Natural and organic chicken, $100 \mathrm{~g} /$ week & - & - & - & + & + & + & + & + \\
\hline Salmon, anchovy, or mackerel, $100 \mathrm{~g} / \mathrm{month}$ & + & - & - & - & - & + & + & + \\
\hline Meat or chicken bouillon & + & - & - & - & - & - & - & - \\
\hline \multicolumn{9}{|l|}{ Vegetable Consumption } \\
\hline Raw greens (lettuce, arugula, parsley, etc.) & + & - & - & - & - & - & - & - \\
\hline Boiled and drained vegetables & - & + & + & + & + & + & + & + \\
\hline $\begin{array}{l}\text { Roasted and dehydrated pepper, eggplant, } \\
\text { tomato, onion, and garlic, } 2 \text { pieces/week }\end{array}$ & - & - & + & + & + & + & + & + \\
\hline Cultivated/red pine mushrooms, $100 \mathrm{~g} /$ week & - & - & + & + & + & + & + & + \\
\hline \multicolumn{9}{|l|}{ Spice and Bitter Consumption ${ }^{c}$} \\
\hline Unsalted green olives, $20 \mathrm{~g} /$ day & - & - & - & + & + & + & + & + \\
\hline $\begin{array}{l}\text { Unsalted isot, black or chili pepper, saffron, } \\
\text { fennel, ginger, turmeric, or cinnamon, } 2 \text { g/day }\end{array}$ & - & - & - & + & + & + & + & + \\
\hline Unsalted sumac or rosemary, $6 \mathrm{~g} /$ day & - & - & - & + & + & + & + & + \\
\hline Cold pressed black seed oil, $1 \mathrm{~g} /$ day & - & - & - & + & + & + & + & + \\
\hline Ketchup, mayonnaise, or salted pickles & + & - & - & - & - & - & - & - \\
\hline Minth and thyme & + & - & - & - & - & - & - & - \\
\hline
\end{tabular}


Table 3. cont.

\begin{tabular}{|c|c|c|c|c|c|c|c|c|}
\hline & Basal & Day 3 & Day 6 & Year 1 & Year 3 & Year 5 & Year 7 & Year 9 \\
\hline & \multicolumn{8}{|c|}{ Hemodialysis-Free Time (9 Years) } \\
\hline \multicolumn{9}{|l|}{ Drinking Habits } \\
\hline Daily alkaline water ( $\mathrm{pH} 7.5-8.5 \mathrm{~mL}$ ) & 1000 & 1500 & 1500 & 1750 & 1750 & 1750 & 1500 & 1750 \\
\hline Fizzy drinks, 3 in 1 coffee, mineral water & + & - & - & - & - & - & - & - \\
\hline Linden tea or black tea, $150 \mathrm{~mL} /$ day & + & + & + & + & + & + & + & + \\
\hline Green tea, $200 \mathrm{~mL} /$ week & - & - & - & + & + & + & + & + \\
\hline Fruit or vegetable juices other than apple & + & - & - & - & - & - & - & - \\
\hline Boiled/drained vegetable soup ${ }^{b}, 100 \mathrm{~mL} /$ day & - & + & + & + & + & + & + & + \\
\hline Lentil, chickpea, ezogelin, or tarhana soups & + & - & - & - & - & - & - & - \\
\hline Meat and bone broth soups, $100 \mathrm{~mL} /$ day & - & - & - & + & + & + & + & + \\
\hline \multicolumn{9}{|l|}{ Other Nutritional Habits } \\
\hline Egg white, 3 times/day & - & + & + & + & + & + & + & + \\
\hline Egg yolk, twice/week & - & + & + & + & + & + & + & + \\
\hline Unsalted/unroasted pumpkin seeds, $10 \mathrm{~g} /$ day & - & - & + & + & + & + & + & + \\
\hline Hazelnut, walnut, almond, or cashew $150 \mathrm{~g} /$ week & - & - & + & + & + & + & + & + \\
\hline Unsalted siyez bread, $56 \mathrm{~g} /$ day & - & - & - & + & + & + & + & + \\
\hline White bakery products or white bread & + & + & + & - & - & - & - & - \\
\hline Corn, sunflower, or hazelnut oil/margarine & + & + & + & - & - & - & - & - \\
\hline Cold pressed olive oil, $28 \mathrm{~g} /$ day & + & - & - & + & + & + & + & + \\
\hline Processed sugar, dry legumes, or pollen & + & - & - & - & - & - & - & - \\
\hline Unsalted curd/cottage/tongue cheese, $30 \mathrm{~g} /$ day & - & - & - & + & + & + & + & + \\
\hline
\end{tabular}

a Boiled and drained white cabbage, apple cider vinegar, olive oil, lemon, garlic, and water are used for preparation. ${ }^{\mathrm{b}}$ One serving per day any of the following: spinach, leek, zucchini, artichoke, broccoli, purslane, white cabbage, celery, or okra. ${ }^{c}$ Maximum three types of spice and bitters can be used on the same day. 


\section{Discussion}

Despite improved dialysis technology and treatment, mortality rates for hemodialysis patients are still high. The survival of elderly patients on maintenance dialysis has been found to be only 26.6 months [1].

Most patients diagnosed with AKI can leave hemodialysis within the first 6 months [6]. However, before the patient applied to us, she was diagnosed with dialysis-dependent ESKD, which was secondary to the diabetic nephropathy diagnosed by a medical doctor in a state hospital who specialized in hemodialysis and internal medicine. The diagnosis of diabetic nephropathy was based on clinical findings. We could not find a renal biopsy. Moreover, the patient received pre-dialysis care for 20 months before starting dialysis. In addition, a permanent vascular access, an AV fistula, was created during this pre-dialysis care in preparation for hemodialysis. Under normal conditions, the first dialysis initiation is not wrong for a patient with an ESKD diagnosis due to diabetic nephropathy, who has uncontrolled hypertension, and whose GFR value is below $10 \mathrm{~mL} / \mathrm{min} / 1.73 \mathrm{~m}^{2}$. However, based on the patient's medical documents and data, we could not conclude whether the decision of the chronic hemodialysis program was incorrect or too early for the present case. Many patients with CKD may develop AKI and are erroneously labeled as having reached ESKD and becoming dialysis-dependent $[5,7,8]$. Perhaps the present case had AKI on CKD and had dialysis at an early stage. For the patient, the eGFR at the start of dialysis was $8.4 \mathrm{~mL} / \mathrm{min} / 1.73 \mathrm{~m}^{2}$, which may be considered as ESKD.

The reasons that caused us to terminate our patient's hemodialysis treatment are multifactorial. In our case, one of the most important factors when terminating dialysis was the regulation of the patient's fluid balance. The continued hemodialysis was accompanied by a reduction in residual kidney function and a progressive deterioration in kidney function. Many patients that may have a potential for renal function recovery (RFR) are missed because of incorrect measurements of ideal dry weight, unnecessary fluid restriction, excessive use of diuretics, or lack of monitoring of residual kidney function $[1,5,7,8]$. Most of these reasons may be valid for our patient.

In our patient, daily fluid intake was restricted during the 6-month period when she underwent hemodialysis, and fluid was removed from her body via ultrafiltration in each dialysis session. All of these are factors could lead to a further increase in renal perfusion disorder, which may be present in elderly patients such as ours. Moreover, it could decrease the amount of urine and impair renal functions. After increasing the patient's oral fluid intake, removing ultrafiltration, and ending hemodialysis, a significant increase was observed in our patient's urine amount (Table 1).

In addition, appropriate nutrition, lifestyle changes, rational drug use, and alternative treatments may be among the beneficial factors effective in terminating dialysis in our patient. We increased the duration of exercise, corrected the disturbed sleep pattern, enabled her to sunbathe and siesta, and treated the depression and anxiety without using medication. The patient stopped her high salt intake, and kidney-friendly spices, bitter, and lemon were added instead. Consumption of frozen or canned meats, processed meats, mineral water, and salty pickles were halted and replaced with kidney-friendly drinks, soups, and meats. We banned white baked goods and white bread, and normalized low vitamin $\mathrm{D}$ and magnesium levels.

All follow-up examinations and tests of the patient were performed by the same nephrologist. In addition, we provided spiritual support to our patient and her caregiver, training them through our care program (Figure 1). In our case, the potential pathomechanisms behind the recovery of renal function may have been caused by better control of diabetes and hypertension. Further, recovery may have resulted from restricting a high salt died, increasing exercise, and raising the patient's fluid intake. All of these may have a positive effect on renal function, as they decrease oxidative stress and proteinuria, and increase renal perfusion. In addition, some alternative treatments that we provided to the patient-such as special sauerkraut and black seed oil-may have had a positive effect on increasing renal perfusion, decreasing oxidative stress, proteinuria, creatinine, and urea levels, and may have had a positive effect on renal recovery $[9,10]$. Previous studies have indicated that probiotic 
consumption may improve gastrointestinal function and slow CKD progression [9]. Moreover, black seed oil may protect kidneys in patients with diabetic nephropathy such as our patient [10].

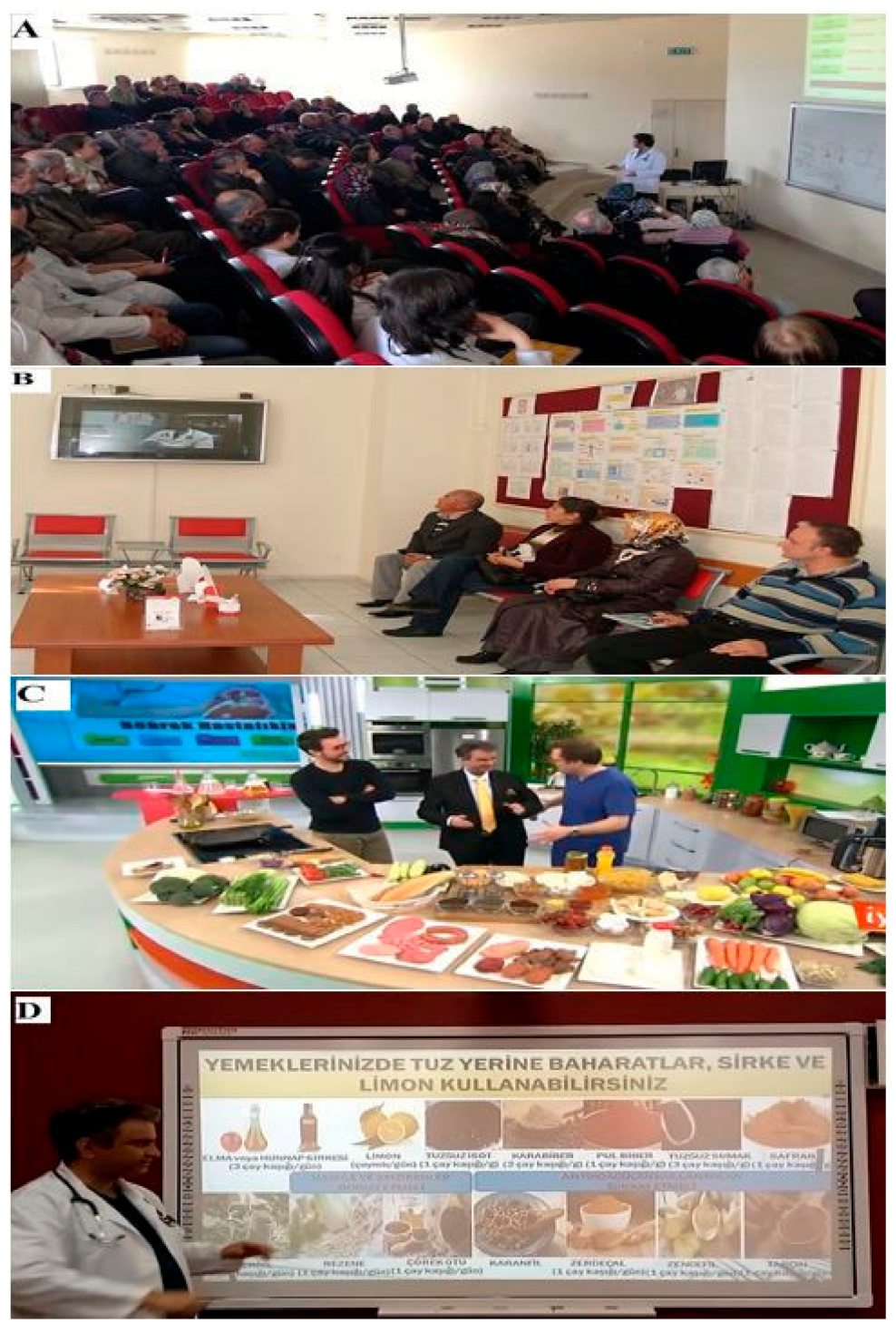

Figure 1. (A) One of the educational patient and caregiver conferences at the hospital; (B) nephrology outpatient clinic education television; (C) one of the national television programs about patient and caregiver education and diet; and (D) one of the educational social media videos for patients and caregivers. All of these videos and conferences above were made by and belong to us. The person seen in the video thumbnail is the corresponding author of the case report. We obtained permission from the patients and the television program's production company to use the screen capture. The source of the TV program is TRT-1 TV.

Another interesting aspect of the case is that before the patient applied to us, she stated to her dialysis doctor that she wanted to come to us in order to reduce or stop the dialysis. The medical doctors in the dialysis center said that it would be suicidal to make such an attempt; dialysis, the doctor argued, could only end when one received a kidney transplant. He advised her to stay away from medical charlatans. However, contrary to what our colleagues say, we followed-up the patient for 9 years without dialysis. If this patient we are presenting had not applied to us, she would have probably continued dialysis.

What are the barriers preventing the discontinuation of hemodialysis in clinical practice? We indicated several, as follows: the lack of RFR knowledge; false belief that ESKD patients could never 
discontinue dialysis; not evaluating the possibility of RFR of the patient by nephrologists, particularly when a patient transfers to a new outpatient center; a lack of the extra effort needed to obtain medical records pertaining to dialysis initiation; financial reasons; the dialysis industry; a lack of optimal care needed for AKI patients who continue to require dialysis after hospital discharge; no guidelines regarding RFR monitoring in dialysis patients [5,7-11]. There are studies that support the above considerations. Numerous case reports and registries have cited RFR delays in dialysis-dependent patients. According to recent studies and large-scale registries, $0.3 \%$ to $8 \%$ of patients with ESKD receiving long-term dialysis recover some degree of kidney function, allowing for the discontinuation of dialysis for a varying period of time and even permanently [1,7,8,11-14].

This case is just the tip of the iceberg. Thousands of patients are on dialysis unnecessarily. It is an extremely dangerous and risky situation to decide to stop dialysis treatment in a presumed ESKD patient because of the risk of death. Naturally, nobody wants to take this risk. There are no guidelines for the cessation of dialysis. In our case, before terminating our patient's dialysis, serum creatinine values were high and around $5 \mathrm{mg} / \mathrm{dL}$ on average. If the patient we removed from dialysis had had any complications such as a brain hemorrhage or a heart attack, we could perhaps have been accused of malpractice. Unfortunately, about 2 weeks after we terminated the patient's dialysis, the doctors at the dialysis center complained to the nephrology association and requested them to open an investigation against us, saying that we risked the patient's life by removing her from dialysis.

This is where the importance of Toprak's Kidney Care comes into play. Secondary to our 17 years of nephrology experience, we have created a care program for CKD patients known as Toprak's Kidney Care [5]. The corresponding author of this study has been working as the only nephrologist for 14 years in the hospital due to the lack of academic staff. For this reason, the follow-up and treatment of all patients are carried out by the same nephrologist. This leads to a stronger connection with the patients and their caregivers, increased control of the nephrologist over their patients and patient follow-up files, and more successful patient follow-ups. In addition, the corresponding author of the study is also experienced and trained in nutrition and spiritual care for CKD patients. The diets of the patients, their calorie intake, daily protein, carbohydrate, and fat needs, as well as their fluid and electrolyte balance, are regulated by the nephrologist who cares for the patients. With the spiritual support given in this case, the depression and anxiety of the patient and her caregiver were eliminated without the need for medication. This also may have played a role in the success of patient follow-up. The fact that approximately 7000 pre-dialysis patients have been followed-up by us (the GFR value of most of these patients is below $15 \mathrm{~mL} / \mathrm{min}$ ) has given us a great deal of experience in pre-dialysis patient follow-up and has led to the emergence of Toprak's Kidney Care. We could not find any other study or information in the literature examining so many pre-dialysis patients who were followed-up by a single nephrologist. As a result of our experience, we use many new practices that are not currently available in the literature, such as a special probiotic sauerkraut, black seed oil, and jujube tea (Table 3). As a result of their use, we have observed that patients experience improved renal function. We hope that we can continue to make clearer recommendations regarding these alternative practices as a result of placebo-controlled studies.

We organize a patient's lifestyle, medications, and diet so that they do not enter dialysis or enter dialysis late, and we train patients and their relatives with Toprak's Kidney Care. Most patients starting dialysis do not receive adequate kidney care beforehand [13]. Although the present case received pre-dialysis care for 20 months, we saw that she had many issues such as high salt intake, consumption of processed foot, and frozen or canned meats, etc. One of the most important features of Toprak's Kidney Care is that we not only educate the patients but we also check whether our recommendations are implemented. In each outpatient clinic appointment, we review in detail whether our guidelines for eating, drinking, lifestyle, and medication are implemented using a standardized questionnaire. We closely follow the patients not only in terms of nephrology but also comorbid diseases. When necessary, we hospitalize our patients and request consultation from relevant branches. For example, in this case, infections requiring hospitalization were successfully treated in a nephrology 
clinic. We attach importance not only to the care of the patient but also to the education of the caregiver, as in our case. The more patients and caregivers know about CKD, the more they avoid habits that can damage the kidneys. This situation may cause patients to have better kidney function. As such, we are in contact with our patients 24/7. In addition, we hold question and answer sessions with patients throughout the day. Our patients do not use any medication or supplements without our approval. Nephrotoxic drug use, excessive salt consumption, and smoking are almost nonexistent in patients in our care program.

The conferences for CKD patients and their caregivers that we organize every month at the hospital are also useful for educating patients. We explain almost everything they need to eat and drink, as well as what they need to do for a healthy life. On March 5th 2020, we held our 133rd education conference. We share these conferences on social media with live broadcast for patients who cannot attend. We also use local and national TV channels to educate patients. We prepared 18 educational videos for CKD patients and their caregivers based on thousands of questions asked by patients about lifestyle, eating and drinking habits, and medication use. By sharing these videos on social media, we enable our patients to watch them at home. In the training videos, we use a language that patients can easily understand and not jargon-heavy medical language. In addition, while the patients and their caregivers wait for examination at the hospital, they also watch our training videos on our training television in the waiting room (Figure 1). No fees are charged to patients or their relatives for all these educational activities. We do our job fondly and reflect this love to our patients and their caregivers. In summary, we use every opportunity we have for the education of our patients.

Many patients with CKD caused by diabetic nephropathy do not have small kidneys, as the present patient did [15]. In our case, a reduction in kidney size was seen on a control ultrasound. When we removed our patient from dialysis, there was no improvement in kidney function, and GFR values were still low. There are no reports in the literature reporting that dialysis was terminated using a patient care program. Only one study showed that three CKD patients with a low protein diet had RFR and cessation of dialysis [12].

The limitation of this case study is that the treatment approaches we used here may not have the same effect on every patient. The strength of this case is that we demonstrated that a dialysis patient can be removed from dialysis and integrated into a patient care program, thus enabling the discontinuation of dialysis despite decreased kidney function.

\section{Conclusions}

The possibility of terminating hemodialysis in patients with ESKD who have a sufficient urine output should not be ignored. Further, patient care may also be considered during the termination of dialysis in these patients. Toprak's Kidney Care may be considered during the recovery of kidney function and dialysis discontinuation in patients with residual kidney function to avoid unnecessary, complicated, and expensive dialysis.

Author Contributions: O.T., B.A.: data collection and writing; O.T., E.A.B.: conception and design of the study, acquisition of data, and analysis and interpretation of data; O.T., E.A.B.: concept and critical review; O.T., B.A., E.A.B.: final approval of the version to be submitted. All authors have read and agreed to the published version of the manuscript.

Funding: This research received no external funding.

Institutional Review Board Statement: Ethical review and approval were waived for this study, due to case report.

Informed Consent Statement: Written informed consent has been obtained from the patient to publish this paper.

Data Availability Statement: All data are included in the manuscript.

Conflicts of Interest: The authors declare no conflict of interest. 


\section{References}

1. Chandrashekar, A.; Ramakrishnan, S.; Rangarajan, D. Survival analysis of patients on maintenance hemodialysis. Indian J. Nephrol. 2014, 24, 206-213. [CrossRef] [PubMed]

2. Johns, T.S.; Yee, J.; Smith-Jules, T.; Campbell, R.C.; Bauer, C. Interdisciplinary care clinics in chronic kidney disease. BMC Nephrol. 2015, 16, 161. [CrossRef] [PubMed]

3. Imamura, Y.; Takahashi, Y.; Hayashi, T.; Iwamoto, M.; Nakamura, R.; Goto, M.; Takeba, K.; Shinohara, M.; Kubo, S.; Joki, N. Usefulness of multidisciplinary care to prevent worsening renal function in chronic kidney disease. Clin. Exp. Nephrol. 2019, 23, 484-492. [CrossRef] [PubMed]

4. Takagi, W.H.; Osako, K.; Machida, S.; Koitabashi, K.; Shibagaki, Y.; Sakurada, T. Inpatient educational program delays the need for dialysis in patients with chronic kidney disease stage G5. Clin. Exp. Nephrol. 2020. [CrossRef] [PubMed]

5. Toprak, O.; Kirik, A. Is renal function recovery and discontinuation of long term hemodialysis possible in patients with presumed end stage kidney disease? The role of Toprak's Kidney Care. J. Urol. Ren. Dis. 2020, 5,1191 .

6. Bhatraju, P.K.; Zelnick, L.R.; Chinchilli, V.M.; Moledina, D.G.; Moledina, D.G.; Parikh, C.R.; Garg, A.X.; Hsu, C.Y.; Go, A.S.; Liu, K.D.; et al. Association between early recovery of kidney function after acute kidney injury and long-term clinical outcomes. JAMA Netw. Open 2020, 3, e202682. [CrossRef] [PubMed]

7. Mohan, S.; Huff, E.; Wish, J.; Lilly, M.; Chen, S.C.; McClellan, W.M. Recovery of renal function among ESRD patients in the US medicare program. PLoS ONE 2013, 8, e83447. [CrossRef] [PubMed]

8. Letachowicz, K.; Madziarska, K.; Letachowicz, W.; Krajewska, M.; Penar, J.; Kusztal, M.; Gołębiowski, T.; Weyde, W.; Klinger, M. The possibility of renal function recovery in chronic hemodialysis patients should not be overlooked: Single center experience. Hemodial. Int. 2016, 20, E12-E14. [CrossRef] [PubMed]

9. Nelson, K.; Wysocki, J. Benefits of probiotic consumption on chronic kidney disease. J. Ren. Nutr. 2020, 30, e35-e36. [CrossRef] [PubMed]

10. Ansari, Z.M.; Nasiruddin, M.; Khan, R.A.; Haque, S.F. Protective role of Nigella sativa in diabetic nephropathy: A randomized clinical trial. Saudi. J. Kidney Dis. Transpl. 2017, 28, 9-14. [CrossRef] [PubMed]

11. Chan, D.T.; Chan, C.T. How does a patient's primary renal disease impact chronic dialysis management?: Primary renal diseases and renal recovery. Semin. Dial. 2015, 28, 468-470. [CrossRef] [PubMed]

12. Piccoli, G.B.; Guzzo, G.; Vigotti, F.N.; Capizzi, I.; Clari, R.; Scognamiglio, S.; Consiglio, V.; Aroasio, E.; Gonella, S.; Veltri, A.; et al. Tailoring dialysis and resuming low-protein diets may favor chronic dialysis discontinuation: Report on three cases. Hemodial. Int. 2014, 18, 590-595. [CrossRef] [PubMed]

13. Craven, A.M.; Hawley, C.M.; McDonald, S.P.; Rosman, J.B.; Brown, F.G.; Johnson, D.W. Predictors of renal recovery in Australian and New Zealand end-stage renal failure patients treated with peritoneal dialysis. Perit. Dial. Int. 2007, 27, 184-191. [CrossRef] [PubMed]

14. Chu, J.K.; Folkert, V.W. Renal function recovery in chronic dialysis patients. Semin. Dial. 2010, $23,606-613$. [CrossRef] [PubMed]

15. Shahbazian, H.; Rezaii, I. Diabetic kidney disease; review of the current knowledge. J. Renal. Inj. Prev. 2013, 2, 73-80. [PubMed]

Publisher's Note: MDPI stays neutral with regard to jurisdictional claims in published maps and institutional affiliations.

(C) 2021 by the authors. Licensee MDPI, Basel, Switzerland. This article is an open access article distributed under the terms and conditions of the Creative Commons Attribution (CC BY) license (http://creativecommons.org/licenses/by/4.0/). 